\title{
Metabolic profiling of Mytilus galloprovincialis and its potential applications for pollution assessment
}

\author{
Oliver A. H. Jones ${ }^{1, *}$, Francesco Dondero ${ }^{2}$, Aldo Viarengo ${ }^{2}$, Julian L. Griffin ${ }^{1}$ \\ ${ }^{1}$ The Hopkins Building, Department of Biochemistry, University of Cambridge, Tennis Court Road, Cambridge CB2 1QW, UK \\ ${ }^{2}$ Department of Environmental and Life Science (DiSAV), University of Piemonte Orientale, Amedeo Avogadro, \\ Via Bellini 25G, 15100 Alessandria, Italy
}

\begin{abstract}
Monitoring of the marine environment is crucial for determining the impact of environmental stressors and/or pollution on ecosystem health. Classical assays that traditionally focus on a limited number of selected endpoints have thus far proven to be of limited success in this regard. Here, we apply ${ }^{1} \mathrm{H}$-nuclear magnetic resonance (NMR)-based chemometric analysis to the marine mussel Mytilus galloprovincialis to investigate changes in the metabolic profile of digestive gland tissue as a response to exposure to nickel and chlorpyrifos, both as single chemicals and as a mixture. The multivariate data was analysed by principal component analysis and partial least-squares discriminant analysis. The major metabolite changes responsible for the spectral differences observed were related to amino acid, nucleotide and methylamine metabolism in all 3 cases. In addition, novel metabolic profiles were associated with exposure to each chemical and the mixture. Nickel produced changes in energy metabolism while chlorpyrifos resulted in an increase in acetylcholine levels. Mussels exposed to a single compound demonstrated a significantly different response to those given the mixture, where a small antagonistic effect was evident. The study demonstrates the potential of NMR-based metabolomics to provide a rapid and cost-effective screening tool for monitoring the aquatic environment.
\end{abstract}

KEY WORDS: Antagonism - Metabonomics - Metabolomics · Mussels · Pollution · Nickel · Chlorpyrifos

\section{INTRODUCTION}

Traditional environmental monitoring approaches have attempted to develop biomarkers by measuring specific responses in well-characterised test organisms (indicator/sentinel species) as indicators of the health of an area. The majority of studies to date have focused mainly on single tests, for example assessing lysosomal membrane stability (LMS) to test for the activation of catabolic processes or measuring glutathione peroxidase levels to test for oxidative stress (Tsangaris et al. 2007). These types of approaches have previously been used in international marine biomonitoring programmes such as MEDPOL phase III, RAMOGE and
OSPAR (Roose \& Brinkman 2005). However, they have proven to be of limited success due to the small number of responses assessed and the variability inherent in all biological/ecological studies.

High-resolution proton nuclear magnetic resonance $\left({ }^{1} \mathrm{H}-\mathrm{NMR}\right)$ spectroscopy-based metabolomics measures the metabolic profiles of cells, tissues, biofluids (and even whole organisms), in conjunction with computer-assisted pattern recognition techniques, to identify metabolic differences between sample groups (Fiehn 2002). The technique has several in-built advantages in environmental assessment in that it is a rapid and cost-effective analytical technique which enables the concentrations of a wide range of small- 
molecule metabolites to be considered simultaneously. NMR-based metabolomics is becoming increasingly prevalent in environmental toxicology research, particularly in terrestrial studies (Griffin \& Shore 2007). The uses and applications of this technique in marine science to date are limited but are summarised in Viant (2007).

Mussels are well-suited to metabolomic analysis for environmental toxicology. They have a wide geographical distribution in both salt and freshwaters and, as sessile, filter-feeding organisms, they are exposed to and bio-accumulate many different classes of environmental contaminants. This, in conjunction with their importance as a food organism to humans, means they are widely used in ecological and bio-monitoring studies (Viarengo \& Canesi 1991, Cajaraville et al. 2000). Therefore integrating ecotoxicogenomics-based data derived from metabolomics into environmentally relevant results is likely to be much easier for these species than for many others.

In the present study, we applied ${ }^{1} \mathrm{H}-\mathrm{NMR}$-based metabolomic and chemometric analysis to the marine mussel Mytilus galloprovincialis. Changes in the metabolic profile of digestive gland tissue as a response to exposure to the heavy metal nickel (Ni) and the organophosphorus insecticide chlorpyrifos (Chlp), both singly and as a mixture, were assessed. Both compounds occur in the marine environment and their effects are currently being assessed in a wide range of species as part of the European Union's NoMiracle project (see http://nomiracle.jrc.it) on mixture toxicity. The goals of the present study were to: (1) metabolically profile $M$. galloprovincialis using NMR, (2) ascertain how this metabolic profile changed in response to exposure to $\mathrm{Ni}$ and Chlp, and whether a combination of both would have synergistic or antagonistic effects and (3) assess the potential of NMR-based metabolomics as a rapid and economical screening tool for monitoring the marine environment.

\section{MATERIALS AND METHODS}

Sample collection. To eliminate potentially confounding effects of sex and age, we used only adult female mussels (Mytilus galloprovincialis [Mollusca; Bivalvia]) that had not spawned. Individual mussels of 4 to $6 \mathrm{~cm}$ length were obtained from a governmentcertified mussel farm in Cesenatico, Italy during February and March 2006. They were then transferred to aquaria at the University of Piemonte Orientale, where they were kept in similar conditions to that of the farm. The tanks were maintained at $16^{\circ} \mathrm{C}$, under natural light, with re-circulating aerated seawater that was collected offshore and changed every $2 \mathrm{~d}$. They were fed every day throughout the study with a commercial algal preparation (Liquifry No. 2, Interpret).

The mussels were acclimatised to the aquaria for $4 \mathrm{~d}$, and then exposed for $4 \mathrm{~d}$ to either no treatment $\left(\mathrm{H}_{2} \mathrm{O}\right.$ control) or $\mathrm{EC}_{50}$ levels of either $\mathrm{Ni}$ (as $\mathrm{NiCl}_{2}$ ) or Chlp (as chlorpyrifos-ethyl) at concentrations of $0.77 \mathrm{mg} \mathrm{l}^{-1}$ $(13.25 \mu \mathrm{M})$ and $4.5 \mathrm{mg} \mathrm{l}^{-1}(12.80 \mu \mathrm{M})$ respectively. These levels had previously been determined to be the $\mathrm{EC}_{50}$ levels for effects on LMS for each toxicant (calculated from dose-fitting analysis). In the case of the equitoxic mixture exposures $\mathrm{Ni}$ and $\mathrm{Chlp}$ were combined at concentrations of $0.135 \mathrm{mg} \mathrm{l}^{-1}(1.65 \mu \mathrm{M})$ and $0.61 \mathrm{mg} \mathrm{l}^{-1}(1.70 \mu \mathrm{M})$. These were the $\mathrm{EC}_{25}$ levels for each chemical in terms of effects on LMS.

Tissue metabolite extraction. Following $4 \mathrm{~d}$ of compound exposure, the mussels were removed from their tanks and the digestive gland of each was rapidly dissected $(<30 \mathrm{~s})$ and flash-frozen in liquid nitrogen. The samples were then stored at $-80^{\circ} \mathrm{C}$ prior to analysis. Although gills are the major site of uptake for waterborne pollutants, the digestive gland was chosen for analysis in this case since it is the main organ utilised for the long-term storage of persistent toxicants (such as heavy metals) and is also involved in detoxification of organic pollutants. ${ }^{1} \mathrm{H}-\mathrm{NMR}$ spectra of adductor muscle, mantle and gill tissue from Mytilus galloprovincialis can be seen in Hines et al. (2007a). The gonads of each mussel were also checked by microscopy during dissection to ensure only female mussels were used.

For metabolite extraction a $100 \mathrm{mg}$ subsample of each gland was crushed to a fine powder under liquid nitrogen using a mortar and pestle. Metabolites were extracted from this powder using a methanol-chloroform procedure (Le Belle et al. 2002). Samples were mixed with $600 \mu \mathrm{l}$ of a methanol-chloroform mixture $(2: 1 \mathrm{v} / \mathrm{v})$ and sonicated for $15 \mathrm{~min}$. A $200 \mu \mathrm{l}$ aliquot of both chloroform and water were then added to the samples, which were centrifuged for $20 \mathrm{~min}$ at $13200 \mathrm{rpm}(12662 \times g)$. The resultant aqueous fractions were then transferred to separate Eppendorf tubes.

High-resolution ${ }^{1}$ H-NMR analysis. The aqueous extracts were dried overnight in a Concentrator 5301 evacuated centrifuge (Eppendorf). They were then reconstituted in $500 \mu \mathrm{l}$ of $\mathrm{D}_{2} \mathrm{O}$ (Goss Scientific Instruments). Since NMR chemical shifts are sensitive to $\mathrm{pH}$, $100 \mu \mathrm{l}$ of $\mathrm{D}_{2} \mathrm{O}$ buffered in $240 \mathrm{mM}$ sodium phosphate, $\mathrm{pH}$ 7.0, containing $0.25 \mathrm{mM}$ sodium (3-trimethylsilyl)2,2,3,3-tetradeuteriopropionate (TSP) (Cambridge Isotope Laboratories) was also added. The TSP acts as an internal standard and also provided a chemical shift reference $(\delta=0.0)$ for the NMR spectra, while the $\mathrm{D}_{2} \mathrm{O}$ provides a deuterium lock for the NMR spectrometer.

Samples were place in individual $5 \mathrm{~mm}$ NMR tubes (Sigma-Aldrich) and analysed using a Varian INOVA 
spectrometer at a proton frequency of $400 \mathrm{MHz}$ using a $5 \mathrm{~mm}$ probe. The pulse sequence was a standard 1D NOESY experiment (relaxation delay $=1.5 \mathrm{~s} ; t 1=4 \mu \mathrm{s}$; mixing time $=100 \mathrm{~ms}$ ). Solvent presaturation was applied during both the relaxation delay and mixing time for the purposes of water suppression. For each sample 128 transients were collected into $64 \mathrm{k}$ data points using a spectral width of $10 \mathrm{ppm}$ at $37^{\circ} \mathrm{C}$.

The resulting 1-dimensional spectra were processed using a macro written within the ACD NMR manager software (Advanced Chemistry Development). The FID (free induction decay) values were multiplied by an exponential weighting function equivalent to $1 \mathrm{~Hz}$ line broadening and Fourier-transformed from the time to the frequency domain. The spectra were then manually phased, baseline-corrected and referenced to the TSP singlet at $0 \mathrm{ppm}$. Areas of the spectrum $<0$ ppm and $>9.5$ ppm were removed since they contained little data of interest. The region between 4.5 and $5 \mathrm{ppm}$ was also excluded in order to avoid the residual $\mathrm{H}_{2} \mathrm{O}$ region, since this is highly variable area of the spectrum due to solvent suppression.

Resonances in the spectra were assigned with reference to chemical shift tables and analysis of related species in the literature (Viant et al. 2003, Hines et al. $2007 a, b)$. Prior to multivariate analysis the spectra were converted into numerical vectors, representing the individual metabolites, by integrating across the spectrum using $0.04 \mathrm{ppm}$ integral regions (bins). To account for any concentration differences between samples the binned intensities were normalised to the total integral region. Individual integrals were thereby standardised to the total integral of all low-weight molecular metabolites.

Acetylcholinesterase determination. Results from the NMR analysis indicated a change in acetylcholine levels but the acetylcholine peak in the NMR spectra was partially obscured by overlapping resonances from other choline residues. We therefore conducted an evaluation of the acetylcholinesterase (AChE) activity in digestive gland extracts using the Acetylcholinesterase Reagent Kit (Ikzus), based on the method of Ellman (1959). Briefly, $1 \mathrm{~g}$ of tissue was homogenised using a motor-driven Teflon/glass PotterElvehjem homogeniser, in a 1:5 ratio with a Tris $\mathrm{HCl}$ $\mathrm{pH} 7.6$ buffered solution, containing $0.1 \%$ Triton X100. Fifty $\mu$ of the cleared supernatant, obtained by centrifugation at $13200 \mathrm{rpm}(12662 \times g)$ for $20 \mathrm{~min}$ at $4^{\circ} \mathrm{C}$, were used for the determination of AChE activity in a phosphate buffered solution ( $\mathrm{pH}$ 7.0) containing Ellman's reagent (2,2-di-thio-nitrobenzoic acid) and $2 \mathrm{mM}$ acetylthiocholine as substrate. Absorption at $412 \mathrm{~nm}$ was recorded for $10 \mathrm{~min}$ in a Varian CaryUV50 spectrophotometer. The absorption contribution from spontaneous hydrolysis of both substrate and sul- phydrylic groups present in the sample were subtracted from the final result. Data were expressed as nanomoles of thiocholine formed per min per mg of protein. The total protein content of the supernatant was determined using Bradford's reagent using bovine serum albumin as a reference standard.

Multivariate data analysis. The metabolic data were imported into SIMCA-P (version 11, Umetrics) and Pareto-scaled. This weights each integral region, or variable, by $\left(1 / S_{d}\right)^{1 / 2}$, where $S_{d}$ is the standard deviation of the variable. This results in an increase in the representation of lower concentration metabolites in the resultant data models, without a corresponding increase from regions largely containing noise.

Multivariate analysis was carried out using principal component analysis (PCA) and partial least-squares discriminant analysis (PLS-DA). These are linear transformations which can be used to visualise similarities and differences in large datasets. They substantially reduce the complexity of data in which a large number of variables are interrelated, which makes them ideal for metabolic studies. The principal components (PCs) are weighted, mutually orthogonal, linear combinations of each of the original variables so that the original data matrix is compressed into a smaller number of 'latent variables'. The weight given to each variable within a PC describes how influential that variable is in relation to the other variables. When displayed graphically on a scores plot, samples with similar scores, and hence similarly correlated metabolic changes, will cluster together and away from groups with different scores (Eriksson et al. 1999). Multivariate techniques are frequently used for metabolomic-based studies as they are able to take into account multiple colinearities within the dataset, where the variation in 1 variable is related to the variation of 1 or more covariables.

PCA is classed as an 'unsupervised technique' since it looks only for inherent variation within the dataset and takes no account of class membership (e.g. whether or not a sample is from the control or exposed group). PLS-DA is a 'supervised' extension of PCA and is used to distinguish 2 or more classes, by searching for variables ( $\boldsymbol{X}$ matrix) which are correlated to class membership ( $\boldsymbol{Y}$ matrix). Since this method does take class membership into account it can be used to examine separation which would otherwise be spread across 3 or more PCs. Supervised techniques require some form of cross-validation to ensure the statistical validity of results. In SIMCA-P this is done through the $\mathrm{Q}^{2}$ parameter, values for which may vary between 0 and 1 (Eriksson et al. 2001). A Q ${ }^{2}$ score of $>0.08$ indicates that the model is significantly better than chance, while a score between 0.7 and 1.0 indicates that the model is highly robust (Eriksson et al. 2001). Similarly, 
the $\mathrm{R}^{2}$ value provides an indication of how much of the variation within a dataset can be explained by the various components of the model as plotted on the $x$ - and $y$-axes. Models were also validated through random permutation of the $\boldsymbol{X}$ matrix (Eriksson et al. 2001). For PLS-DA, the metabolites responsible for the separation (95\% confidence limits) were obtained from the coefficients list using custom-written TCL code.

\section{RESULTS}

\section{${ }^{1} \mathrm{H}-\mathrm{NMR}$ spectroscopy of mussel digestive gland tissue}

A total of 36 metabolites were identified in the digestive gland of Mytilus galloprovincialis via NMR (Fig. 1, Table 1). Several classes of compound were present

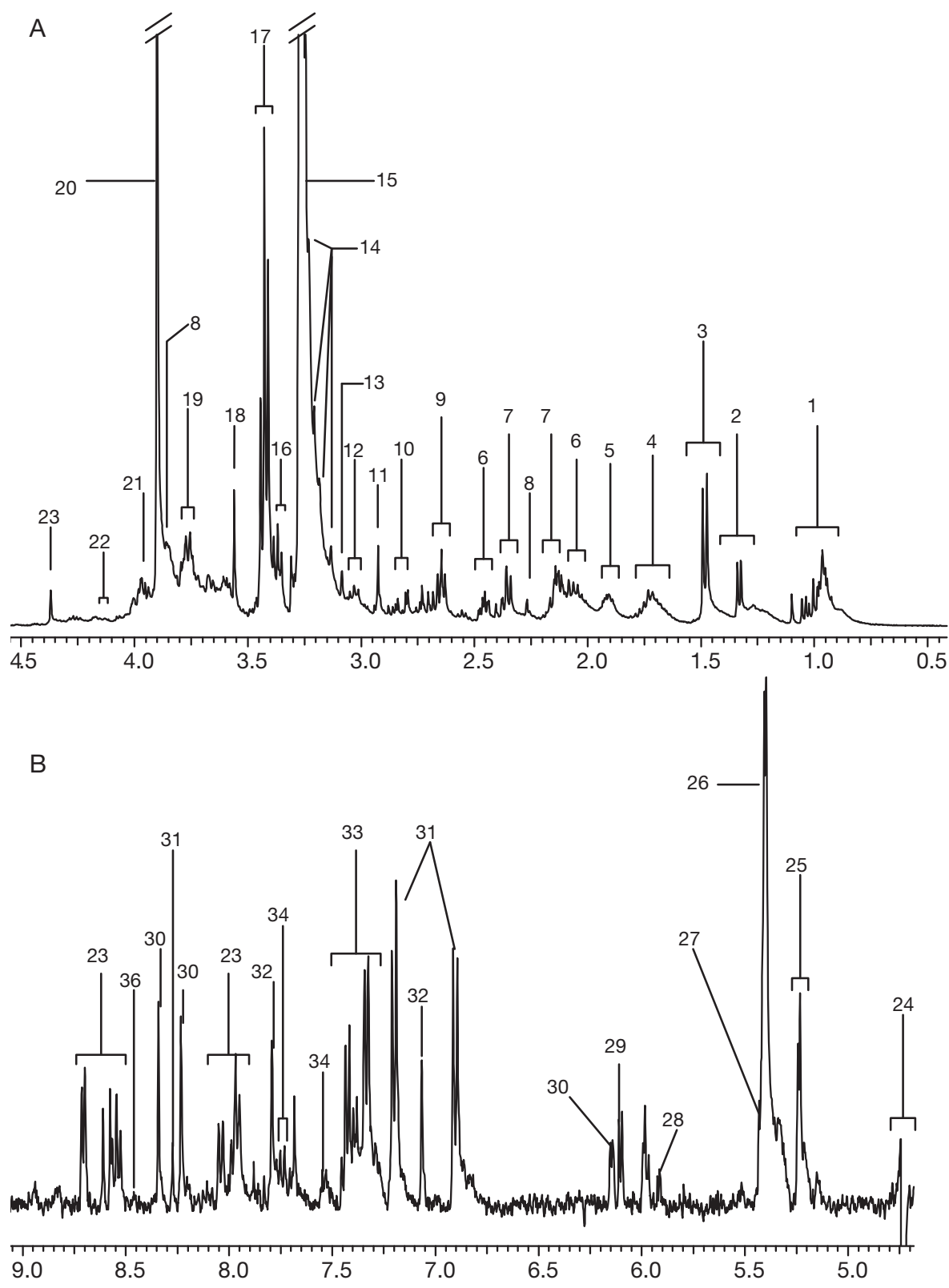

Fig. 1. (A) Representative 1-dimensional $400 \mathrm{MHz}{ }^{1} \mathrm{H}-\mathrm{NMR}$ spectra of a mussel digestive gland exposed to nickel and chlorpyrifos and (B) vertical expansion of the aromatic region. Key to suggested assignments: 1, isoleucine, leucine and valine; 2 , lactate; 3, alanine; 4, arginine; 5, lysine and arginine; 6, glutamate; 7, glutamine; 8, succinate; 9, methionine; 10, aspartate; 11, dimethylglycine; 12, lysine; 13, malonate; 14, overlapping resonances from acetylcholine, choline and phosphocholine; 15, TMAO; 16, hypotaurine; 17, taurine; 18, glycine; 19, phenylacetylglycine; 20, betaine; 21, hippurate; 22, proline; 23, homarine; 24, water peak (suppressed); 25, alpha glucose; 26, allantoin (and some glycogen); 27, glycogen; 28, guanine nucleotides; 29, adenosine nucleotides; 30, ATP and ADP; 31, tyrosine; 32, histidine; 33, phenylalanine; 34, tryptophan; 35, uracil nucleotides; 36, formate 
but all spectra were found to be dominated mainly by the organic osmolyte, trimethylamine oxide (TMAO). Other prominent resonances were betaine, glycine, taurine and choline. Observable metabolic categories included amino acids (e.g. leucine, isoleucine and valine), carbohydrates (e.g. glucose), products of glycolysis (e.g. lactate), tricarboxylic acid (TCA) cycle intermediates (e.g. succinate), organic acids (e.g. formate) and various nucleotides (e.g. adenosine).

\section{Classification of toxicant exposure by multivariate analysis}

For the exposure experiments it was necessary to dissolve Chlp in DMSO for the Chlp and mixture experiments. To test whether DMSO itself could affect metabolism, 1 group of mussels was treated with $0.05 \%$ DMSO (in water) alone $(n=6)$ and compared with the control group. No significant difference was

Table 1. Chemical shifts for the metabolites identified in Fig. 1. $\mathrm{s}=$ singlet, $\mathrm{d}=$ doublet, $\mathrm{dd}=$ double doublet, ddd $=$ doublet of double doublets, $\mathrm{t}=$ triplet, $\mathrm{q}=$ quartet, $\mathrm{m}=$ multiplet, $\mathrm{ABX}=$ complex multiplet involving 2 protons $(\mathrm{A}$ and $\mathrm{B})$ and a heavy atom $(\mathrm{X})$

\begin{tabular}{|c|c|c|c|}
\hline Key & Metabolite & Chemical shift and multiplicity & Source \\
\hline 1 & $\begin{array}{l}\text { Isoleucine } \\
\text { Leucine } \\
\text { Valine }\end{array}$ & $\begin{array}{l}0.94(\mathrm{t}), 1.01(\mathrm{~d}), 1.26(\mathrm{~m}), 1.48(\mathrm{~m}), 1.98(\mathrm{~m}), 3.68(\mathrm{~d}) \\
0.96(\mathrm{~d}), 0.97(\mathrm{~d}), 1.71(\mathrm{~m}), 3.73(\mathrm{t}) \\
1.00(\mathrm{~d}), 1.05(\mathrm{~d}), 2.27(\mathrm{~m}), 3.61(\mathrm{~d})\end{array}$ & $\begin{array}{l}\text { Fan (1996) } \\
\text { Fan (1996) } \\
\text { Fan (1996) }\end{array}$ \\
\hline 2 & Lactate & $1.33(\mathrm{~d}), 4.12(\mathrm{q})$ & Fan (1996) \\
\hline 3 & Alanine & $1.49(\mathrm{~d}), 3.78(\mathrm{~m})$ & Fan (1996) \\
\hline 4 & Arginine & $1.7(\mathrm{~m}), 1.93(\mathrm{~m}), 3.25(\mathrm{t}), 3.77(\mathrm{t})$ & Fan (1996) \\
\hline 5 & Lysine and arginine & See numbers 4 and 12 & \\
\hline 6 & Glutamate & $2.10(\mathrm{~m}), 2.36(\mathrm{~m}), 2.50(\mathrm{~m}), 3.77(\mathrm{t})$ & Fan (1996) \\
\hline 7 & Glutamine & $2.14(\mathrm{~m}), 2.46(\mathrm{~m}), 3.77(\mathrm{t})$ & Fan (1996) \\
\hline 8 & Succinate & $2.43(\mathrm{~s})$ & Fan (1996) \\
\hline 9 & Methionine & $2.14(\mathrm{~s}), 2.16(\mathrm{~m}), 2.65(\mathrm{t}), 3.86(\mathrm{t})$ & Fan (1996) \\
\hline 10 & Aspartate & $2.68(\mathrm{ABX}), 2.82(\mathrm{ABX}), 3.91(\mathrm{ABX})$ & Fan (1996) \\
\hline 11 & Dimethylglycine & $2.78(\mathrm{~s}), 2.93(\mathrm{~s}), 3.72(\mathrm{~s})$ & Lindon et al. (1999) \\
\hline 12 & Lysine & $1.48(\mathrm{~m}), 1.73(\mathrm{~m}), 1.91(\mathrm{~m}), 3.03(\mathrm{t}), 3.76(\mathrm{t})$ & Fan (1996) \\
\hline 13 & Malonate & $3.13(\mathrm{~s})$ & Lindon et al. (1999) \\
\hline 14 & $\begin{array}{l}\text { Overlapping resonances from } \\
\text { choline, acetylcholine, } \\
\text { and phosphocholine }\end{array}$ & $\begin{array}{l}3.21(\mathrm{~s}), 3.52(\mathrm{~s}), 4.07(\mathrm{~m}) \\
2.15(\mathrm{~s}), 3.20(\mathrm{~s}) \\
3.22(\mathrm{~s}), 3.35(\mathrm{~s}), 3 . .52(\mathrm{~m}), 3.61(\mathrm{t}), 3.71(\mathrm{dd}), 3.77(\mathrm{~m}), \\
3,97(\mathrm{~m}), 4.19(\mathrm{t}), 4.37(\mathrm{~m})\end{array}$ & $\begin{array}{l}\text { Viant et al. (2003) } \\
\text { Sze \& Jardetzky (1990) }\end{array}$ \\
\hline 15 & TMAO & $3.27(\mathrm{~s})$ & Fan (1996) \\
\hline 16 & Hypotaurine & $2.66(\mathrm{t}), 3.38(\mathrm{t})$ & Viant et al. (2003) \\
\hline 17 & Taurine & $3.25(\mathrm{t}), 3.43(\mathrm{t})$ & Fan (1996) \\
\hline 18 & Glycine & $3.57(\mathrm{~s})$ & Fan (1996) \\
\hline 19 & Phenylacetylglycine & $3.67(\mathrm{~s}), 3.75(\mathrm{~d}), 7.35(\mathrm{t}), 7.35(\mathrm{~d}), 7.42(\mathrm{t})$ & Nicholls et al. (2003) \\
\hline 20 & Betaine & $3.27(\mathrm{~s}), 3.90(\mathrm{~s})$ & Lindon et al. (1999) \\
\hline 21 & Hippurate & $3.97(\mathrm{~d}), 7.55(\mathrm{t}), 7.64(\mathrm{t}), 7.84(\mathrm{~d})$ & Lindon et al. (1999) \\
\hline 22 & Proline & $2.01(\mathrm{~m}), 2.07(\mathrm{~m}), 2.35(\mathrm{~m}), 3.33(\mathrm{~m}), 3.42(\mathrm{~m}), 4.14(\mathrm{~m})$ & Lindon et al. (1999) \\
\hline 23 & Homarine & $4.37(\mathrm{~s}), 7.98(\mathrm{dd}), 8.04(\mathrm{~d}), 8.55(\mathrm{dd}), 8.72(\mathrm{~d})$ & Viant et al. (2003) \\
\hline 24 & Water peak (suppressed) & $4.79(\mathrm{~s})$ & Lindon et al. (1999) \\
\hline 25 & Alpha glucose & $\begin{array}{l}3.41(\mathrm{t}), 3.53(\mathrm{dd}), 3.71(\mathrm{t}), 3.74(\mathrm{~m}), 3.84(\mathrm{~m}) \\
3.84(\mathrm{ddd}), 5.23(\mathrm{~d})\end{array}$ & Lindon et al. (1999) \\
\hline 26 & Allantoin (and some glycogen) & $5.40(\mathrm{~d})$ & Lindon et al. (1999) \\
\hline 27 & Glycogen & $5.42($ broad s) & Viant et al. (2003) \\
\hline 28 & Guanine & $5.94(\mathrm{~d}), 8.14(\mathrm{~s})$ & Sze \& Jardetzky (1990) \\
\hline 29 & Adenosine & $6.06(\mathrm{~d}), 8.22(\mathrm{~s}), 8.33(\mathrm{~s})$ & Sze \& Jardetzky (1990) \\
\hline 30 & ATP and ADP & $\begin{array}{l}4.3(\mathrm{~m}), 4.34(\mathrm{~m}), 4.42(\mathrm{~m}), 4.55(\mathrm{t}), 4.68(\mathrm{t}), 6.15(\mathrm{~d}) \\
8.26(\mathrm{~s}), 8.54(\mathrm{~s})\end{array}$ & Fan (1996) \\
\hline 31 & Tyrosine & 3.06 (ABX), 3.20 (ABX), $3.94(\mathrm{ABX}), 6.91$ (d), $7.20(\mathrm{~d})$ & Lindon et al. (1999) \\
\hline 32 & Histadine & $\begin{array}{l}3.14(\mathrm{ABX}), 3.2(\mathrm{dd}) 3.25(\mathrm{ABX}), 3.99(\mathrm{ABX}) \\
7.08(\mathrm{~s}), 7.83(\mathrm{~s})\end{array}$ & Fan (1996) \\
\hline 33 & Phenylalanine & $3.13(\mathrm{~m}), 3.28(\mathrm{~m}), 4.00(\mathrm{~m}), 7.33(\mathrm{~m}), 7.38(\mathrm{~m}), 7.43(\mathrm{~m})$ & Fan (1996) \\
\hline 34 & Tryptophan & $\begin{array}{l}3.31(\mathrm{ABX}), 3.49(\mathrm{ABX}), 4.06(\mathrm{ABX}), 7.21(\mathrm{t}), 7.29(\mathrm{t}) \\
7.33(\mathrm{~s}), \\
7.55(\mathrm{~d}), 7.74(\mathrm{~d})\end{array}$ & Lindon et al. (1999) \\
\hline 35 & Uracil & $5.81(\mathrm{~s}), 7.54(\mathrm{~d})$ & Nicholls et al. (2003) \\
\hline 36 & Formate & $8.46(\mathrm{~s})$ & Holmes et al. (1997) \\
\hline
\end{tabular}



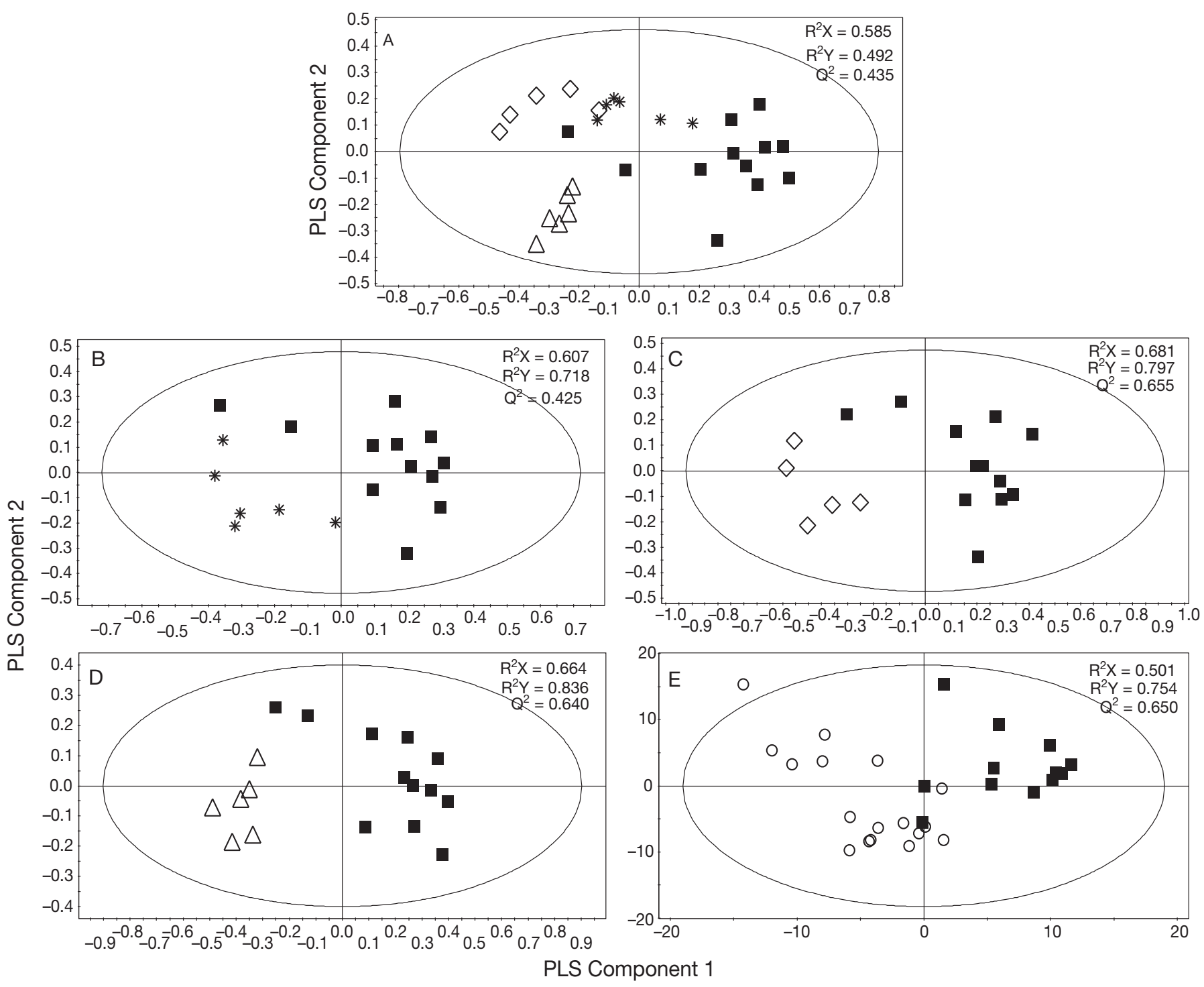

Fig. 2. Partial least-squares discriminant analysis (PLS-DA) model showing (A) separation of the control mussels $(\mathbf{\square}, \mathrm{n}=12 ; 6$ of these animals exposed to DMSO vehicle, 6 no treatment) from those exposed to chlorpyrifos $(\mathrm{Chlp})(*, \mathrm{n}=6), \mathrm{nickel}(\mathrm{Ni})(\diamond, \mathrm{n}=$ 5) and both chemicals $(\Delta, \mathrm{n}=6)_{i}(\mathrm{~B})$ separation of the control mussels ( $\left.\boldsymbol{\square}\right)$ from those exposed to Chlp (*); (C) separation of the control mussels ( $\mathbf{\square})$ from those exposed to $\mathrm{Ni}(\diamond)$; (D) separation of the control mussels $(\boldsymbol{\square})$ from those exposed to both Ni and Chlp

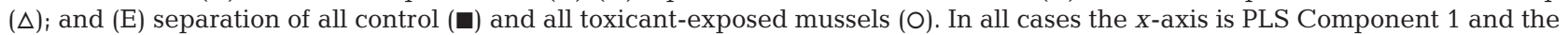
$y$-axis is PLS Component 2

found between the 2 groups using PCA, PLS-DA or visual inspection of the NMR spectra and they were therefore combined to form a single control group $(\mathrm{n}=$ 12) in subsequent analysis.

It was not possible to distinguish between control and toxicant-exposed animals using visual inspection (either by eye on under the microscope) or via physical parameters such as weight (data not shown). PLS-DA resulted in greater separation of each group (Fig. 2A) than PCA and was therefore used throughout this study. This plot demonstrated that NMR spectra from mussels exposed to the single substances separate mainly along PLS component 1 (most correlated variation in the dataset), while those from mussels exposed to both chemicals clustered separately along PLS component 2. This indicates that the metabolic profiles of these individuals are different from both control organisms and those exposed to either of the single compounds. Separation and associated $\mathrm{R}^{2}$ and $\mathrm{Q}^{2}$ scores were all improved by comparing only 2 groups at a time (Figs. 2B-D) and it was also possible to separate all exposed mussels from all control mussels, using the metabolic differences common to all 3 toxic exposures to cluster the groups (Fig. 2E). 

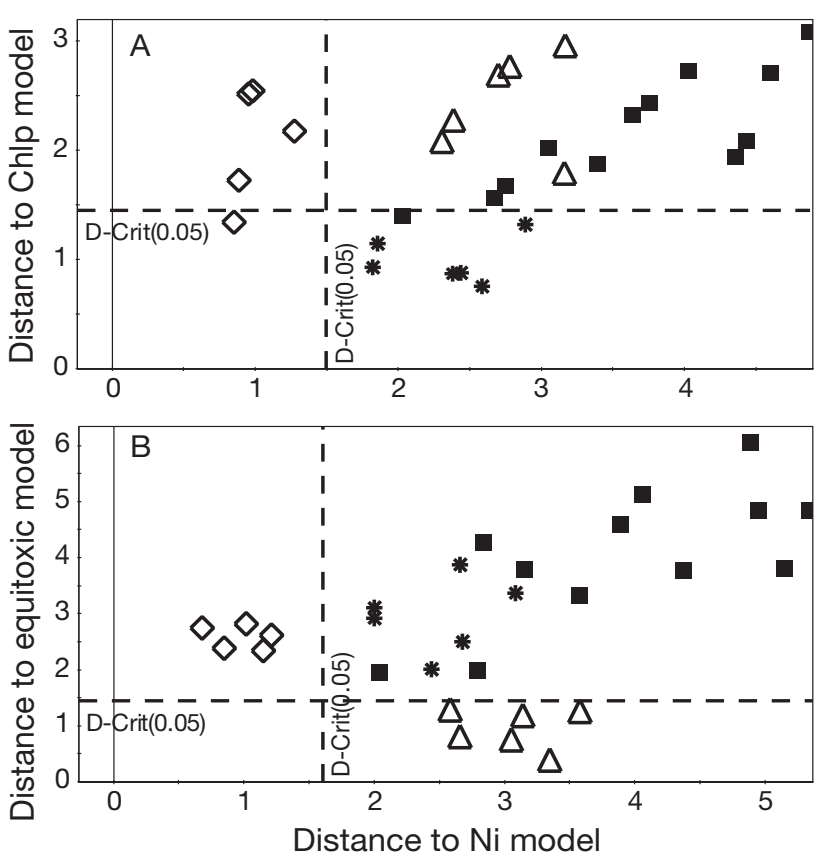

Fig. 3. Cooman's plots created from digestive gland spectra from (A) mussels exposed to Ni $(\diamond, x$-axis) and chlorpyrifos (Chlp) ( ${ }^{*}, y$-axis) and (B) from those exosed to Ni ( $x$-axis) and the equitoxic $(\Delta, y$-axis) samples. ( $\square)$ control samples. In (A) the Chlp samples fall below the horizontal line on the $y$-axis, representing the $95 \%$ confidence limit of the Chlp model, indicating that these samples belong to this class as defined by the model. All other samples are above the line, indicating they do not belong to the Chlp model. Similarly, the Ni samples are to the left of the Ni model line, while everything else is to the right. Samples in the top right corner in each case cannot be explained by either model, while any that fall in the lower left could theoretically be explained by both models. In (B) the results are the same but with the equitoxic samples $(\Delta)$ taking the place of the Chlp samples on the $X$-axis

For all models the control/exposed classification was also tested using 2 Cooman's plots (Fig. 3A,B). For this type of analysis 2 independent PCA models are calculated which define 2 separate classes of samples, in this case $\mathrm{Ni}(x$-axis) and Chlp ( $y$-axis) in Fig. $3 \mathrm{~A}$ and $\mathrm{Ni}$ ( $x$-axis) and equitoxic samples (y-axis) in Fig. 3B. The distances of samples to each of the 2 models are then plotted against each other. This 'distance to model' (DModX) is the summation of residual variation in each of the $x$ variables. Mapping of unknown samples onto the calculated models can then provide the class identity based on the similarity between the unknown samples and the samples in the pre-defined class models (Holmes \& Antti 2002).

The distance to model for the PCA models of either the Chlp-, Ni- or mixture-exposed mussel groups were used to calculate the critical distance (D-Crit) value, representing the multivariate $95 \%$ confidence limit for each group. Samples below the horizontal D-Crit line

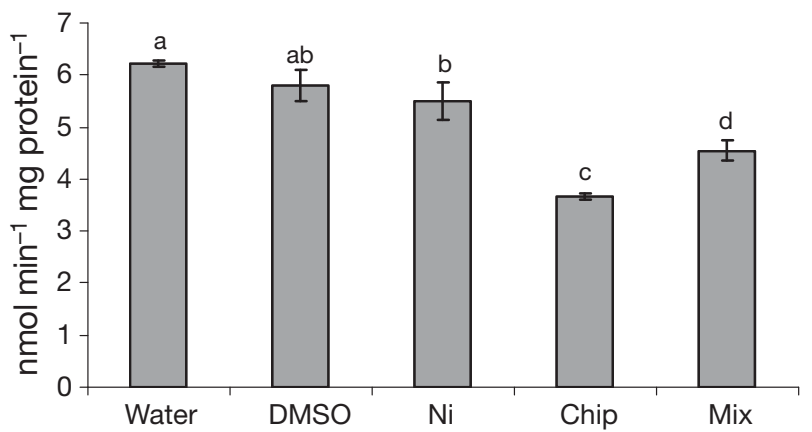

Fig. 4. Changes in acetlycholinesterase activity in response to each compound. Data are mean \pm SE. Groups without a common superscript letter are statistically significant (ANOVA, Bonferroni post hoc test, $\mathrm{p}<0.05, \mathrm{n}=4$ ). Chlp: chlorpyrifos; Ni: nickel; Mix: both Chlp and Ni

belong to the Chlp-exposed group in Fig. 3A and the equitoxic samples in Fig. 3B, while samples to the left of the vertical D-Crit value belong to the Ni-exposed group in both figures. Samples within the bottom left square are classified as part of both groups in each model, and those in the top right box are classified as neither model.

The Cooman's plots were found to accurately describe the class boundaries for the Chlp, Ni and equitoxic samples and correctly identified that the samples that were not used to build the models did not belong to either class or both classes. This again indicates that the metabolic changes induced by exposure to both compounds are distinct from those induced by either compound alone.

A summary of the metabolic perturbations detected in digestive gland tissue exposed to each compound is shown in Table 2.

The NMR analysis indicated a change in acetylcholine levels and this was further investigated by checking the amount of AChE activity in all groups. The results are shown in Fig. 4 and indicate a clear inhibition of AChE in Chlp-exposed mussels as well as those exposed to the mixture, although the effect is noticeably less pronounced in the mixture-exposed mussels.

\section{DISCUSSION}

The results presented here demonstrate the great potential of NMR-based metabolomics to provide a rapid and cost-effective screening tool for marine monitoring. Multivariate statistical analysis of the NMR spectra of mussel digestive gland tissue showed clear differences between the metabolic profiles of individuals exposed to Ni, Chlp and a combination of both chemicals. 
Table 2. List of the metabolites significantly up- or downregulated (using $95 \%$ confidence limits) as a result of toxicant exposure. PAG: phenyl acetyl glycine

\begin{tabular}{|c|c|c|}
\hline Toxicant & $\begin{array}{l}\text { Metabolites } \\
\text { decreased in } \\
\text { exposed samples }\end{array}$ & $\begin{array}{l}\text { Metabolites } \\
\text { increased in } \\
\text { exposed samples }\end{array}$ \\
\hline \multirow[t]{18}{*}{ Nickel } & Allantoin & $\begin{array}{l}\text { Adenosine } \\
\text { nucleotides }\end{array}$ \\
\hline & $\begin{array}{l}\text { Arginine } \\
\text { Betaine }\end{array}$ & $\begin{array}{l}\text { ATP and ADP } \\
\text { Glutamine }\end{array}$ \\
\hline & Glucose & $\begin{array}{l}\text { Guanine } \\
\text { nucleotides }\end{array}$ \\
\hline & Glutamate & Hypotaurine \\
\hline & $\begin{array}{l}\text { Gilycine } \\
\text { Glycogen }\end{array}$ & \\
\hline & Hippurate & \\
\hline & Histidine & \\
\hline & Homarine & \\
\hline & Isoleucine & \\
\hline & Leucine & \\
\hline & Malate & \\
\hline & PAG & \\
\hline & Phenylalanine & \\
\hline & Proline & \\
\hline & Succinate & \\
\hline & Tryptophan & \\
\hline & Tyrosine & \\
\hline & $\begin{array}{l}\text { Uracil nucleotides } \\
\text { Valine }\end{array}$ & \\
\hline \multirow[t]{11}{*}{ Chlorpyrifos } & Arginine & $\begin{array}{l}\text { Adenosine } \\
\text { nucleotides }\end{array}$ \\
\hline & Glutamate & ATP and ADP \\
\hline & Hippurate & Choline(s) \\
\hline & Isoleucine & Glutamine \\
\hline & Lactate & $\begin{array}{l}\text { Guanine } \\
\text { nucleotides }\end{array}$ \\
\hline & Leucine & Homarine \\
\hline & Phenylacetylglycine & \\
\hline & Phenylalanine & \\
\hline & Proline & \\
\hline & Tyrosine & \\
\hline & Valine & \\
\hline \multirow{6}{*}{$\begin{array}{l}\text { Nickel and } \\
\text { chlorpyrifos }\end{array}$} & Adenosine nucletides & Alanine \\
\hline & Beta-hydroxybutyrate & Choline(s) \\
\hline & Glutamate & Isoleuceine \\
\hline & Guanine & PAG \\
\hline & Nicotinate & Valine \\
\hline & N-methylnicotinamide & \\
\hline
\end{tabular}

Certain changes were common across all groups. The largest changes were in the concentrations of amino acids. This was particularly noticeable in the Niexposed group where concentrations of many more compounds (27) were affected than in either of the other 2 groups (17 in the Chlp group and 12 in the group exposed to the mixture). In previous toxicology studies in rodents, similar changes in amino acid concentrations indicated a general stress event related to reduced feeding rates of an organism in response to the stress of pollutant exposure (calorie restriction) (Connor et al. 2004). This is further supported by the reduction in the concentrations of malate and succinate in the Ni-exposed group. As facultative anaerobes, mussels can potentially utilise a peculiar carbohydrate fermentation process, with a non-oxidative TCA cycle that works in reverse, from pyruvate up to succinate (De Zwaan et al. 1976). This seems not to be the case here, however, since succinate levels did not increase.

During food restriction, gluconeogenesis is increased to produce glucose from a range of sources, including lactate, amino acids and ketone bodies. This catabolic period is also usually characterised by degradation of lipids, glycogen and protein. However, as discussed by Stuart \& Ballantyne (1996) and Viant et al. (2003), there is some evidence that marine molluscs are less reliant on fatty acid and ketone body metabolism compared with mammals and freshwater molluscs. The physiological basis for this may be that some marine molluscs use high intracellular concentrations of free amino acids to balance their intracellular osmolarity with the environment (Viant et al. 2003) and that these pools of oxidisable amino acids are also used extensively in cellular energy metabolism (Moyes et al. 1990). This is consistent with results seen in starved disk abalone (Haliotis discus) (Watanabe et al. 1993) and in diseased and stunted red abalone $H$. rufescens (Viant et al. 2003).

In the latter study, decreased concentrations of amino acid in diseased abalone were also correlated with increased homarine levels (Viant et al. 2003). The role of homarine in mollusc metabolism is unclear, but it is widely distributed in marine invertebrates and may play a role in osmoregulation (Gasteiger et al. 1960, Hirano 1975). Viant et al. (2003) therefore postulated that the changes they observed may have been a compensatory mechanism to help balance the loss of oxidisable amino acid osmolytes from the intracellular medium.

In the present study, however, the concentration of homarine was not correlated with amino acid levels, since concentrations were decreased in Ni-exposed mussels, increased in Chlp-exposed animals and unchanged in those exposed to both chemicals. It is therefore likely, in mussels at least, that homarine is not used to compensate for the loss of oxidisable amino acids. Given the large amount of methylamine compounds (particularly TMAO) observed in all NMR spectra, it seems likely that compensating for any osmoregulation problems caused by lack of amino acids would not be a problem for mussels, possibly reflecting a different osmoregulatory strategy compared to abalone.

A correlation exists between the concentrations of TMAO and betaine in muscle tissue and lipids levels in 
the bodies of many marine animals (Seibel \& Walsh 2002). No significant decreases in TMAO or betaine were observed in any of the exposure groups, suggesting that the changes in amino acid metabolism observed in the present study are therefore more likely a general stress response to toxicant exposure as previously observed in rats (Connor et al. 2004).

A change in nucleotide metabolism was also detected in all groups. Perturbations of this type have previously been linked to peroxisome proliferation (PP) (Ringeissen et al. 2003). Peroxisomes are ubiquitous organelles in eukaryotes that function to rid the cell of toxic substances. It has been shown that PP occurs in mussels as a consequence of the exposure to polyaromatic hydrocarbons and other organic xenobiotics. However, exposure to Ni and other heavy metals is not thought to induce this effect (Cajaraville et al. 2003). Therefore, it is likely that in the case of $\mathrm{Ni}$ at least, the changes in nucleotide metabolism were caused by something other than PP.

$\mathrm{Ni}$ also induced increases in the concentrations of taurine and hypotaurine. Both compounds play a protective role against peroxidative damage and increases in levels of taurine have been reported in the liver of rats following treatment with various xenobiotics including those which alter protein synthesis and/or are hepatotoxic (Waterfield et al. 1998). Moreover, increased taurine levels associated with decreases in glycine have been previously reported in the posterior muscle tissue of mussels exposed to cadmium and copper (Scholz 1987). This change may be part of the general stress response and relate to the increased use of amino acids in cellular metabolism, which is stronger with $\mathrm{Ni}$ than in any of the other treatments.

Levels of glutamate were decreased with respect to controls in all treatments. Reduced levels of glutamate may be associated with increased glycolytic metabolism and the subsequent utilisation of 2-oxoglutarate formed in the TCA cycle. Glutamate plays an essential role in ammonia homeostasis and is also involved in the synthesis of glutamine and is a constituent of many biologically active oligopeptides such as glutathione, a tripeptide present at high concentrations intracellularly and thought to be involved in cellular mechanisms dealing with oxidative stress. It should be noted that the NMR spectra did not clearly show peaks from glutathione, ascorbate or cysteine (which are the main defences-related metabolites produced in response to oxidative stress). This was due to spectral overlap from larger peaks.

The utilisation of the amino acid pool for energy production is also corroborated by the analysis of gene expression profiles on the same tissues, which indicated a downregulation of cellular carbohydrates metabolising enzymes such as chitinases and cellulases (Dondero et al. 2007).

Chlp exposure involved changes in the concentration of 17 metabolites, and here too most were amino acids and nucleotides. A change specific to Chlp exposure was an increase in acetylcholine levels, which increased in Chlp-exposed mussels compared to controls, presumably in response to the impairment of AChE.

The effects of the mixture of Ni and Chlp on metabolic profiles partially resembled those due to Chlp but involved fewer metabolites (13) and the specific responses to $\mathrm{Ni}$ were not detected. Interestingly, some changes that did occur were different from either of the metabolic differences detected for the individual groups. For example, concentrations of valine, phenylacetyl glycine and isoleucine, which were decreased in Ni- and Chlp- exposed samples, were increased in those exposed to both. There were also increases in nicotinate and $\mathrm{N}$-methylnicotinamide levels which were not seen in response to exposure of either of the single compounds. These unique changes again demonstrate that the metabolic profiles of mussels exposed to both compounds are distinct from those exposed to single compounds.

These changes are mirrored in the gene expression data (Dondero et al. 2007). Mussels exposed to Ni were found to differentially express approximately 120 genes. These were mainly involved in carbohydrate metabolism, proteolysis, ribosome biogenesis and assembly, signal transduction, immune functions and metallothionin production. In contrast Chlp exposure affected a much lower number of genes, mainly involved in aminosugar metabolism, while the effects of the mixture partially resembled those due to Chlp with the specific Ni responses seeming to disappear.

The present study shows NMR-based metabolomics to be a powerful approach for assessing the effects of marine pollution. Representative samples from mussel populations in areas thought to be at risk of contamination could potentially be examined using NMR or similar analytical techniques to ascertain whether they exhibited metabolic changes associated with toxicant exposure. This would be in agreement with the concept of the normal metabolic operating range (NMOR) recently proposed by Viant (2007). The metabolic profiles of those mussels that did show signs of exposure could then be compared with a library of reference spectra from mussels exposed to known toxicants in order to narrow down the list of potential contaminants.

Nevertheless, there are several limitations associated with metabolomics. The metabolic profile of any organism is exceedingly sensitive to external factors such as age, diet, diurnal and reproductive cycles, sex 
and parasite load. For instance the concentrations of TMAO, betaine and other osmolytes have been demonstrated to vary among habitats and species, and even with season and ontogeny within species (Seibel \& Walsh 2002).

The response of a particular organism to toxicants can also vary depending on the prevailing environmental conditions to which it is exposed. Factors such as species, age, sex and reproductive status are well known to affect metabolism and these factors should be taken into account in all environmental metabolomic-based studies (Hines et al. 2007a, Morrison et al. 2007). This is often termed phenotypic anchoring (Paules 2003).

In aquatic organisms, factors such as water organic matter content, salinity, $\mathrm{pH}$ and temperature may all have an effect (Rosenblum et al. 2006). Therefore linking any observed biochemical effects with markers of the overall health of individual organisms will be important in order to assess their ability to predict community- or population-level effects (Allen \& Moore 2004).

Acknowledgements. This research was financially supported by the European Union (European Commission, FP6 Contract No. 003956). J.L.G. is a Royal Society (UK) University Research Fellow. O.A.H.J. is also grateful to Dr. Mahon Maguire for helpful discussions on data processing techniques.

\section{LITERATURE CITED}

Allen JI, Moore MN (2004) Environmental prognostics: Is the current use of biomarkers appropriate for environmental risk evaluation? Mar Environ Res 58:227-232

Cajaraville MP, Bebianno MJ, Blasco J, Porte C, Sarasquete C, Viarengo A (2000) The use of biomarkers to assess the impact of pollution in coastal environments of the Iberian peninsula: a practical approach. Sci Total Environ 247: 295-311

Cajaraville MP, Cancio I, Ibabe A, Orbea A (2003) Peroxisome proliferation as a biomarker in environmental pollution assessment. Microsc Res Tech 61:191-202

> Connor SC, Wu W, Sweatman BC, Manini J, Haselden JN, Crowther DJ, Waterfield CJ (2004) Effects of feeding and body weight loss on the ${ }^{1} \mathrm{H}$-NMR-based urine metabolic profiles of male Wistar Han rats: implications for biomarker discovery. Biomarkers 9:156-179

De Zwaan A, Kluytmans JHFM, Zandee DI (1976) Facultative anaerobiosis in molluscs. Biochem Soc Symp 41:133-168

Dondero F, Jones OAH, Banni M, Boatti L and others (2007) Molecular effects of $\mathrm{Ni}$ and clorpyrifos in the digestive gland tissue of Mytilus galloprovincialis: a systems biology approach. Mar Environ Res 66:139-140

Ellman GL (1959) Tissue sulfhydryl groups. Arch Biochem Biophys 82:70-77

Eriksson L, Johansson E, Kettaneh-Wold N, Wold S (1999) Introduction to multi- and megavariate data analysis using projection methods (PCA and PLS). Umetrics, Umeå

Eriksson L, Johansson E, Kettaneh-Wold N, Wold S (2001)
Multi- and megavariate data analysis: principles and applications, Vol 1. Umetrics, Umeå, Sweden

Fan TWM (1996) Metabolite profiling by one- and twodimensional NMR analysis of complex mixtures. Prog Nucl Magn Reson Spectrosc 28(Spec):161-219

Fiehn O (2002) Metabolomics - the link between genotypes and phenotypes. Plant Mol Biol 48:155-171

Gasteiger EL, Haake PC, Gergen JA (1960) An investigation of the distribution and function of homarine (N-methyl picolinic acid). Ann NY Acad Sci 90:622-636

Griffin JL, Shore RF (2007) Applications of metabonomics within environmental toxicology. In: Lindon JC, Nicholson JK, Holmes E (eds) The handbook of metabonomic and metabolomics. Elsevier Press, Kidlington, UK, p 517-532

Hines A, Oladiran GS, Bignell JP, Stentiford GD, Viant MR (2007a) Direct sampling of organisms from the field and knowledge of their phenotype: key recommendations for environmental metabolomics. Environ Sci Technol 41: 3375-3381

> Hines A, Yeung WH, Craft J, Brown M and others (2007b) Comparison of histological, genetic, metabolomic, and lipid-based methods for sex determination in marine mussels. Anal Biochem 369:175-186

Hirano T (1975) On the distribution and seasonal variation of homarine in some marine invertebrates. Nippon Suisan Gakkai Shi 41:1047-1051

> Holmes E, Antti H (2002) Chemometric contributions to the evolution of metabonomics: mathematical solutions to characterising and interpreting complex biological NMR spectra. Analyst (Lond) 127:1549-1557

Holmes E, Foxall PJD, Spraul M, Duncan Farrant R, Nicholson JK, Lindon JC (1997) $750 \mathrm{MHz}{ }^{1} \mathrm{H}$ NMR spectroscopy characterisation of the complex metabolic pattern of urine from patients with inborn errors of metabolism: 2-hydroxyglutaric aciduria and maple syrup urine disease. J Pharm Biomed Anal 15:1647-1659

> Le Belle J, Harris N, Williams S, Bhakoo K (2002) A comparison of cell and tissue extraction techniques using highresolution ${ }^{1} \mathrm{H}-\mathrm{NMR}$ spectroscopy. NMR Biomed 15:37-44

Lindon JC, Nicholson JK, Everett JR (1999) NMR spectroscopy of biofluids. In: Webb GA (ed) Annual reports on NMR spectroscopy, Vol 38. Academic Press, London, p 1-88

Morrison N, Bearden D, Bundy J, Collette T and others (2007) Standard reporting requirements for biological samples in metabolomics experiments: environmental context. Metabolomics 3:203-210

Moyes CD, Suarez RK, Hochachka PW, Ballantyne JS (1990) A comparison of fuel preferences of mitochondria from vertebrates and invertebrates. Can J Zool 68:1337-1349

Nicholls AW, Mortishire-Smith RJ, Nicholson JK (2003) NMR spectroscopic-based metabonomic studies of urinary metabolite variation in acclimatizing germ-free rats. Chem Res Toxicol 16:1395-1404

> Paules R (2003) Phenotypic anchoring: linking cause and effect. Environ Health Perspect 111:A338-A339

> Ringeissen S, Connor SC, Brown HR, Sweatman BC and others (2003) Potential urinary and plasma biomarkers of peroxisome proliferation in the rat: identification of $\mathrm{N}$-methylnicotinamide and N-methyl-4-pyridone-3-carboxamide by ${ }^{1} \mathrm{H}$ nuclear magnetic resonance and high performance liquid chromatography. Biomarkers 8: 240-271

> Roose P, Brinkman UAT (2005) Monitoring organic microcontaminants in the marine environment: principles, programmes and progress. Trends Anal Chem 24:897-926

Rosenblum ES, Tjeerdema RS, Viant MR (2006) Effects of 
temperature on host-pathogen-drug interactions in red abalone, Haliotis rufescens, determined by ${ }^{1} \mathrm{H}$ NMR metabolomics. Environ Sci Technol 40:7077-7084

Scholz N (1987) Significance of the taurine-glycine ratio as an indicator of stress. Bull Environ Contam Toxicol 38:15-21

Seibel BA, Walsh PJ (2002) Trimethylamine oxide accumulation in marine animals: relationship to acylglycerol storage. J Exp Biol 205:297-306

Stuart JA, Ballantyne JS (1996) Correlation of environment and phylogeny with the expression of [beta]-hydroxybutyrate dehydrogenase in the mollusca. Comp Biochem Physiol B 114:153-160

Sze DY, Jardetzky O (1990) Determination of metabolite and nucleotide concentrations in proliferating lymphocytes by ${ }^{1} \mathrm{H}-\mathrm{NMR}$ of acid extracts. Biochim Biophys Acta 1054: 181-197

Tsangaris C, Papathanasiou E, Cotou E (2007) Assessment of the impact of heavy metal pollution from a ferro-nickel

Editorial responsibility: Inna Sokolova,

Charlotte, North Carolina, USA smelting plant using biomarkers. Ecotoxicol Environ Saf 66:232-243

Viant MR (2007) Metabolomics of aquatic organisms: the new 'omics' on the block. Mar Ecol Prog Ser 332:301-306

Viant MR, Rosenblum ES, Tjeerdema RS (2003) NMR-based metabolomics: a powerful approach for characterizing the effects of environmental stressors on organism health. Environ Sci Technol 37:4982-4989

Viarengo A, Canesi L (1991) Mussels as biological indicators of pollution. Aquaculture 94:225-243

Watanabe H, Yamanaka H, Yamakawa H (1993) Changes in the content of extractive components in disk abalone fed with marine algae and starved. Nippon Suisan Gakkai Shi 59:2031-2036

Waterfield CJ, Asker DS, Patel S, Timbrell JA (1998) Is there a correlation between taurine levels and xenobioticinduced perturbations in protein synthesis? A study with tetracycline in rats. Amino Acids 15:161-177

Submitted: December 4, 2007; Accepted: July 16, 2008 Proofs received from author(s): September 17, 2008 